\title{
CONHECIMENTOS INDÍGENAS E O PENSAMENTO DE BOAVENTURA DE SOUZA SANTOS: REFLEXÕES A PARTIR DE PROCESSOS DE FORMAÇÃO DE PROFESSORES/AS ${ }^{1}$
}

BEATRIZ OSORIO STUMPF ${ }^{2}$

UNIR, BRASIL

https://orcid.org/0000-0001-8510-5511

\begin{abstract}
RESUMO: $O$ artigo desenvolve reflexões sobre conhecimentos indígenas identificados ao longo de processos investigativos participativos na área da formação de professores/as, tecendo relações com o pensamento de Boaventura de Souza Santos. A discussão ocorre através de três experiências desenvolvidas na Amazônia brasileira, sendo dois cursos de formação continuada e uma disciplina de Licenciatura Indígena Intercultural. A partir de categorias do pensamento do autor, como Sociologias das Ausências e das Emergências, Ecologia de Saberes e Teoria da Tradução, o texto apresenta ideias sobre a importância dos conhecimentos indígenas para mudanças de pensamento necessárias à educação e à sociedade, bem como sobre os impactos ocasionados a esse conjunto de saberes por processos colonizadores e homogeneizantes da racionalidade hegemônica. Além disso, destaca a potencialidade investigativa de experiências de formação de professores/as indígenas, demonstrada através dessas trajetórias de participação, interlocuções e reflexões.
\end{abstract}

PALAVRAS-CHAVE: Formação, Professores Indígenas, Boaventura de Souza Santos.

ABSTRACT: The article develops reflections on indigenous knowledge identified through participatory research processes in the area of teacher training, linking with the thinking of Boaventura de Souza Santos. The discussion takes place through three experiences developed in the Brazilian Amazon, two continuing education courses and one Intercultural Indigenous Licentiate course. From the categories of the author's thinking, such as Sociologies of Absences and Emergencies, Ecology of Knowledge and Translation Theory, the text presents ideas about the importance of indigenous knowledge for the changes of thought necessary for education and society, as well as for the impacts caused to this set of knowledge by colonizing and homogenizing processes of hegemonic rationality. In addition, it highlights the research potential of experiences of indigenous teacher training, demonstrated through these trajectories of participation, dialogues and reflections.

KEYWORDS: Formation, Indigenous Teachers, Boaventura de Souza Santos.

\footnotetext{
${ }^{1}$ O presente trabalho foi realizado com apoio da Coordenação de Aperfeiçoamento de Pessoal de Nível Superior - Brasil (CAPES) - Código de Financiamento 001.

${ }^{2}$ Doutoranda do Programa de Pós-Graduação em Educação (PPGEDU) da Universidade de Santa Cruz do Sul (UNISC). E-mail: beatriz.osoriostumpf@yahoo.com.br
} 


\section{Introdução}

Este texto desenvolve reflexões sobre conhecimentos indígenas identificados ao longo de processos investigativos participativos na área da formação de professores/as, tecendo relações com categorias do pensamento de Boaventura de Souza Santos.

A discussão ocorre a partir de três experiências desenvolvidas na Amazônia brasileira, sendo dois cursos de formação continuada de professores/as indígenas no alto rio Negro, São Gabriel da Cachoeira/AM; e uma disciplina do Curso de Licenciatura Indígena Intercultural da Universidade do Estado do Pará (UEPA), Tucuruí/PA.

A parte inicial da narrativa oferece uma contextualização, caracterizando os processos formativos que originaram a discussão, destacando elementos importantes para as observações posteriores. A segunda seção tece reflexões sobre conhecimentos indígenas, desenvolvendo diálogos a partir de observações e depoimentos de professores/as participantes dos cursos, no entrelaçamento com categorias do pensamento de Boaventura de Souza Santos, como Ecologia de Saberes e Teoria da Tradução, dentro da perspectiva das Sociologias das Ausências e das Emergências.

O último momento reúne as principais considerações alcançadas a partir das observações e diálogos, bem como do processo reflexivo e de escrita, trazendo ideias sobre a importância dos conhecimentos indígenas para mudanças de pensamento necessárias à educação e à sociedade, bem como sobre os impactos ocasionados a esse conjunto de saberes por processos colonizadores e homogeneizantes da racionalidade hegemônica. Além disso, destaca a potencialidade investigativa de experiências de formação de professores/as indígenas, demonstrada através dessas trajetórias de participações, interlocuções e reflexões.

\section{Contextualizações}

A reflexão transcorre a partir do acompanhamento participativo e investigativo de três processos de formação de professores/as indígenas, com diferentes graus de atuação da autora do texto, os quais são explicados na descrição de cada trabalho.

As investigações utilizam metodologia inspirada na pesquisa-ação, cujas vantagens para área da educação são abordadas por Engel (2000, p. 183), por contribuir para uma pesquisa engajada, que integra teoria e prática, buscando alcançar resultados funcionais relevantes para cada situação. Todas as atividades foram acompanhadas por registros em diário de campo, com observações, depoimentos e percepções, dentro de um objetivo mais amplo de conhecimento e compreensão do pensamento ameríndio e das relações interculturais envolvidas em trabalhos de formação de professores/as indígenas.

A opção metodológica dessas trajetórias formativas se direcionou para uma diversidade de estratégias que proporcionasse espaços de discussão e de construção de métodos, instrumentos e materiais 
pedagógicos para a Educação Escolar Indígena, de acordo com as demandas e potenciais de cada contexto. A participação ativa nessas formações, de forma integrada a processos de investigação, possibilitou intensa observação e reflexão sobre o encontro entre diferentes culturas e visões de mundo em propostas de construção coletiva intercultural.

Segue uma breve contextualização de cada uma das experiências que deram origem à discussão:

\section{Aperfeiçoamento em Educação Escolar Indígena}

Esta experiência se refere à participação da autora como professora e organizadora em duas etapas de formação continuada de professores/as indígenas desenvolvidas nos anos de 2015 e 2016, pelo Instituto Federal de Educação, Ciência e Tecnologia do Amazonas (IFAM) - Campus São Gabriel da Cachoeira/AM, através da ação "Saberes Indígenas na Escola", uma política pública educacional do governo brasileiro $^{3}$ integrada ao Programa Nacional dos Territórios Etnoeducacionais Indígenas ${ }^{4}$, no Eixo Pedagogias diferenciadas e uso de línguas indígenas. As atividades ocorreram no município de São Gabriel da Cachoeira, Estado do Amazonas, alto rio Negro, extremo noroeste da Amazônia brasileira, fronteira com Colômbia e Venezuela.

Conforme a Portaria $n^{\circ}$ 98, de 06 de dezembro de 2013, esse programa nacional ocorre em regime de colaboração com os Estados, o Distrito Federal, Municípios e Institutos de Ensino Superior, trabalhando pela promoção dos direitos dos povos indígenas à educação escolar diferenciada, reconhecendo e valorizando sua diversidade sociocultural e linguística, autonomia e protagonismo, por meio do fortalecimento de territórios etnoeducacionais.

Através de formação continuada para professores indígenas, mais especificamente os que atuam nos anos iniciais, a ação visa proporcionar apoio pedagógico, contribuindo para o aperfeiçoamento docente, principalmente em métodos de alfabetização, letramento e etnomatemática. A formação é direcionada para pesquisas que resultem na produção de materiais didáticos e paradidáticos específicos. 0 programa também oferece subsídios à elaboração de currículos, definição de metodologias e sistemas de avaliação que atendam às peculiaridades dos processos pedagógicos e dos conhecimentos dos povos indígenas. Esse processo formativo torna possível a ampliação do atendimento na perspectiva de aperfeiçoamento pedagógico de professores indígenas, contribuindo para a melhoria de suas atuações educacionais nas escolas,

\footnotetext{
3 A ação Saberes Indígenas na Escola é uma Política Pública Nacional de formação continuada de professores/as indígenas, a qual foi instituída pela Portaria $\mathrm{n}^{\circ} 98$, de 06 de dezembro de 2013. http://www.lex.com.br/legis_25162523_PORTARIA_N_98_DE_6_DE_DEZEMBRO_DE_2013.aspx

${ }^{4}$ O Programa Nacional dos Territórios Etnoeducacionais Indígenas (TEE) foi instituído pelo Decreto 6.861, de 2009, visando apoiar a implementação, avaliação e fortalecimento da Política de Educação Escolar Indígena, considerando a territorialidade das etnias, participação indígena e integração entre os órgãos públicos. O TEE foi pensado como um espaço de articulação das políticas públicas voltadas à Educação Escolar Indígena, envolvendo seus diferentes atores e agentes na discussão e planejamento conjunto das ações. http://www.funai.gov.br/index.php/educacao-escolar-indigena?start=7.
} 
instrumentalizando-os e propiciando espaços de construção para uma prática pedagógica diferenciada.

A Ação Saberes Indígenas na Escola está fundamentada nos princípios de especificidade, organização comunitária, multilinguismo e interculturalidade. A formação desenvolvida pelo IFAM - polo São Gabriel da Cachoeira, por meio dessa política pública, ocorreu de forma integrada às ações do movimento educacional indígena existente na região, em seu processo de construção de uma educação escolar diferenciada. Portanto, de acordo com as especificidades regionais, foram acrescentados outros princípios: concepção sistêmica de educação, interdisciplinaridade, ação reflexiva em conexão com a realidade, autonomia e ensino através da pesquisa.

Esse processo formativo contemplou 60 professores indígenas alfabetizadores, no período 2015-2016, no curso denominado "Aperfeiçoamento em Educação Escolar Indígena". Em virtude das grandes distâncias das comunidades, a formação ocorreu de forma intensiva, distribuída em duas etapas, e contemplando atividades de pesquisa entre elas. A primeira etapa contou com 120 horas de trabalho, desenvolvidas ao longo de quinze dias, com abordagem introdutória de todas as áreas, incluindo concepções metodológicas como o ensino pela pesquisa, com orientações e planejamentos para o trabalho de campo. No período entre as etapas, os/as professores/as desenvolveram atividades de pesquisa nas comunidades onde lecionam, de acordo com temas previamente escolhidos, registrando os dados obtidos. Na segunda etapa, com um total de 80 horas, ao longo de dez dias, foram trabalhados os registros trazidos pelos/as participantes, através de dinâmicas construtivas, para a elaboração coletiva de métodos de ensino e de materiais didáticos.

Participaram desta formação professores indígenas das etnias: Yanomami, Baré, Tukano, Tariano, Dessano, Piratapuia, Kuripaco e Baniwa. Considerando esta grande diversidade de etnias, com suas especificidades, foram organizados grupos de trabalho, de modo a permitir a construção coletiva de materiais didáticos específicos para cada etnia, contemplando suas línguas e características, respeitando e valorizando a potencialidade etnolinguística da região. Foram oferecidos elementos para a construção de concepções de ensino, métodos e materiais didáticos para a educação escolar indígena diferenciada das etnias participantes. Estes elementos correspondem às áreas $\mathrm{da}$ alfabetização, letramento e ciências da natureza. Foi abordada uma concepção de integração entre estas temáticas, principalmente a partir das disciplinas "Elementos para a construção da Escola Indígena Diferenciada" e "Educação Multiciclada".

Para a apresentação dos subsídios e a criação de contextos de elaboração de métodos e matérias, foram utilizados métodos diversos, como aula expositiva dialogada com uso de recursos audiovisuais, dinâmicas de grupo, apresentação de estudos de caso das escolas diferenciadas já consolidadas, trocas de experiências, jogos de aprendizagem, entre outros. A metodologia de trabalho se constituiu também, de forma processual e coletiva, através do compartilhamento de conhecimentos pelos pesquisadores indígenas, orientadores de estudo, 
coordenações e professores alfabetizadores cursistas, considerando suas realidades pedagógicas, sociolinguísticas e antropológicas. Durante todo o processo os professores formadores atuaram como pesquisadores, com o uso de diários de campo para o registro de suas observações.

\section{Fortalecendo Escolas Indígenas Hupd’äh, Yuhup' dëh e Dâw}

Aqui a participação da autora ocorre na forma de idealizadora, coordenadora e formadora no projeto de extensão "Fortalecendo Escolas Indígenas Hupd'äh, Yuhupdëh e Dâw”, do Instituto Federal do Amazonas (IFAM), Campus São Gabriel da Cachoeira / Núcleo Gestor de Estudos Linguísticos e Antropológicos (NUGLAN), em parceria com a Secretaria Municipal de Educação e Cultura de São Gabriel da Cachoeira (SEMEC), a Fundação Nacional do Índio (FUNAl), a Federação das Organizações Indígenas do Rio Negro (FOIRN) ${ }^{5}$ e membros do Coletivo de apoio aos povos Yuhup' dëh e Hupd 'äh (CAPYH) ${ }^{6}$.

Esse projeto de extensão consiste em um programa de formação continuada de professores/as indígenas, direcionado para etnias indígenas de recente contato ${ }^{7}$ do alto rio Negro, em São Gabriel da Cachoeira, AM, tendo como objetivo contribuir para o fortalecimento da Educação Escolar Indígena Diferenciada dessas etnias. Desde sua elaboração até a execução, a atuação reflete uma visão de construção a partir das demandas, respeito aos hábitos e valores étnicos, relação com atores locais e caráter multidimensional, envolvendo a integração entre diversas dimensões, como educação, saúde, assistência social, direito, política, economia e cultura, com o trabalho solidificado na articulação entre diferentes áreas de conhecimento, assim como na construção interinstitucional e intercultural, com participação de indígenas de variadas etnias e não indígenas.

Apesar de serem etnias de recente contato, atualmente os povos Hupd'äh e Yuhupdëh frequentam muito a sede do município, principalmente em busca de benefícios sociais, sem possuir ainda os conhecimentos necessários para circular no meio urbano, como o domínio da língua portuguesa e do modo de lidar com dinheiro, cartões bancários e documentos. Essa questão, aliada à falta de estrutura adequada para sua recepção e manutenção na cidade, tem ocasionado o envolvimento em uma série de problemas, como doenças, uso abusivo de álcool, endividamento, exploração por parte de comerciários, acidentes e alto índice de suicídio. Esses indígenas chegam a permanecer vários meses acampados para resolver seus problemas, muitas vezes sem

\footnotetext{
${ }^{5}$ A FOIRN é uma organização criada em 1987 como resultado do movimento pela demarcação de uma terra indígena contínua, a qual tem por objetivo a defesa dos direitos coletivos dos povos indígenas da região.

${ }^{6} \mathrm{O}$ CAPYH constitui um grupo não institucionalizado que desenvolve ações de assessoria a esses povos em São Gabriel da Cachoeira, formado por pesquisadores/as dessas populações e profissionais de diferentes áreas que atuam ou atuaram diretamente com eles através de instituições acadêmicas, órgãos públicos e organizações não governamentais.

${ }^{7} \mathrm{O}$ termo "Etnias de recente contato" se refere a grupos indígenas que apresentam especificidades em sua relação com a sociedade nacional e alto grau de autonomia na relação com o Estado (FUNAI, 2012).
} 
recursos para retornar às suas comunidades. Geralmente ficam em local próximo à cidade, conhecido como "beiradão", uma área na margem do rio Negro, com grande incidência de malária, diarreia e outras doenças, sem infraestrutura sanitária adequada, acesso à água potável e coleta de resíduos sólidos.

A iniciativa do Programa de Formação Continuada "Fortalecendo Escolas Indígenas Hupd'äh, Yuhup 'dëh e Dâw" emergiu da convivência, diálogo e ações conjuntas entre representantes dessas etnias e profissionais de diferentes áreas de conhecimento, como antropologia, pedagogia, psicologia e assistência social, membros do Coletivo de apoio aos povos Yuhup'dëh e Hupd'äh (CAPYH). O convívio emergiu da moradia temporária conjunta em uma residência, a qual também consistia em ponto de apoio para essas etnias quando vinham para a cidade, onde obtinham orientação e acompanhamento do grupo para resolver questões relacionadas com documentação e benefícios sociais. Através da convivência foi possível discutir sobre suas demandas, anseios, dificuldades e potencialidades, constituindo a base para a construção do projeto, o qual foi apresentado ao IFAM, através do Núcleo Gestor de Estudos Linguísticos e Antropológicos (NUGLAN), na forma de projeto de extensão, integrado a uma proposta de pesquisa.

A partir dos diálogos com a Secretaria de Educação foi verificada a sua dificuldade em realizar o acompanhamento de todas as escolas das comunidades da região, devido às enormes distâncias, grande número de escolas, poucos profissionais e escassos recursos. Essa instituição proporcionou materiais e profissionais para participação na formação, com escuta das demandas, explicações e informações. A FUNAI disponibilizou recursos para alimentação e combustível para o deslocamento dos professores. A FOIRN forneceu o local para o curso e a cozinha para o preparo das refeições. O IFAM propiciou professores de diversas áreas de conhecimento e uma parte do material.

O projeto tem como objetivo contribuir para o fortalecimento da Educação Escolar Indígena Diferenciada das etnias Nadawhup ${ }^{8}$ da região do alto rio Negro, através de formação continuada de professores. A estratégia da formação se fundamenta em um processo de diálogo intercultural, na forma de espaços de reflexão, construção e mediação para o fortalecimento de escolas indígenas diferenciadas, de acordo com as especificidades dessas etnias, conforme seus interesses, necessidades e estágios de desenvolvimento das escolas. As atividades são conduzidas de forma a possibilitar a expressão das demandas existentes, a partir das quais é continuamente construído e implementado o processo de formação, abrangendo assessoria pedagógica, subsídios e elementos de apoio. A abordagem envolve um conjunto diversificado de métodos,

\footnotetext{
${ }^{8}$ As etnias Hupd'äh, Yuhup' dëh e Dâw fazem parte da unidade linguística "Maku". Recentemente, algumas iniciativas têm se voltado para a mudança do nome dessa família linguística na busca de um substituto para o termo "Maku", considerando seu conteúdo pejorativo e o fato de não ter sua legitimidade reconhecida pelas próprias populações que são assim designadas. A palavra Maku significa "aquele que não tem língua" ou "aquele que não sabe nossa língua", sendo a denominação dada pelos Tukano para se referir a esses povos. Epps (2005) propõe o termo "Nadawhup" para a família composta pelos Maku da área brasileira, o qual é utilizado neste texto, apesar de ainda estar em discussão.
} 
incluindo técnicas participativas, dinâmicas de grupo, atividades artísticas e culturais, vivências, elaboração de mapas, construção de materiais didáticos e exposições dialogadas com apresentação de imagens e filmes.

Devido às grandes distâncias das comunidades Hupd'äh e Yuhupdeh, as ações são centralizadas no município de São Gabriel da Cachoeira, proporcionando a troca interétnica de ideias e experiências entre os/as participantes, mas também contemplando atividades de construção organizadas na forma de grupos de trabalho, específicos para cada etnia. As etapas da formação são realizadas nos períodos de férias escolares, aproveitando a época em que muitos professores se encontram no município para resolver suas questões de documentação e contratação, contribuindo para o apoio a esta estada na cidade, oferecendo local de estadia, alimentação, atividades e orientações.

Desse modo, a formação continuada ocorre em um formato de ciclos semestrais, envolvendo um circuito de reflexão, ação e avaliação. A partir de subsídios teóricos, ilustrativos e práticos, junto a atividades reflexivas e construtivas, é proporcionada uma base para a ação dos/as professores/as em suas comunidades. A cada seis meses são realizadas novas etapas de avaliação, formação e planejamento, em que os/as participantes apresentam seus resultados, dificuldades e avanços, possibilitando a troca de experiências, que apontam elementos para a ação docente.

Os programas são desenvolvidos com uma visão interdisciplinar e intercultural, reunindo teoria e prática, de forma conectada aos temas de interesse dos povos indígenas e das comunidades dessas etnias, principalmente no que se refere a território, ambiente, sustentabilidade, saúde, cultura e ética. Os assuntos estão organizados na forma de eixos temáticos conectados entre si. Esses eixos e seus respectivos conteúdos correspondem à integração entre as diversas áreas de conhecimento e temas transversais, conforme o Referencial Curricular Nacional para as Escolas Indígenas (BRASIL, 1988), documento elaborado com a participação de indígenas de diversas etnias brasileiras.

Durante as etapas de 2015 e 2016 foram trabalhados os seguintes eixos temáticos: "Pedagogia Intercultural"; "Alfabetização, Letramento e Literatura Multilíngue"; "Etnomatemática, Matemática e Numeramento"; "Pluralidade Cultural"; "Direitos, Lutas e Movimentos"; "Terra, Conservação da Biodiversidade e Auto-sustentação"; "Educação e Relação com Sociedade". Os eixos "Alfabetização, Letramento e Literatura Multilíngue" e "Etnomatemática, Matemática e Numeramento" foram repetidos por solicitação dos/as participantes durante a avaliação da primeira etapa. A repetição desses eixos foi realizada com a produção de novas versões, elaboradas de modo a oferecer outros tipos de subsídios e atividades, proporcionando o aprofundamento de conhecimentos, exercícios e produção de materiais. 


\section{Disciplina "Interculturalidade na Educação Escolar Indígena"}

Essa experiência corresponde à participação da autora como professora da disciplina "Interculturalidade na Educação Escolar Indígena", da Licenciatura Intercultural Indígena da Universidade do Estado do Pará (UEPA), em turma da etnia Assurini do Tocantins, na aldeia Trocará, município de Tucuruí/PA. O processo proporcionou, através de um conjunto de dinâmicas construtivas e reflexivas, a elaboração coletiva de ideias, métodos e materiais pedagógicos para a educação escolar intercultural.

A disciplina contemplou o uso de uma diversidade de métodos, incluindo filmes, apresentações dialogadas, leituras de textos, discussões, caminhadas pela aldeia, pesquisa, produção textual, construção de materiais pedagógicos e planos de aula, além de apresentações de trabalhos. Entre as produções, pode ser destacada a elaboração de um Levantamento Socioambiental, inspirado no trabalho do Instituto Socioambiental (ISA), e a construção de um Calendário Socionatural, um dos instrumentos pedagógicos que fazem parte do Método Indutivo Intercultural ${ }^{9}$. Todas as atividades foram permeadas por reflexões, com trocas de ideias entre os/as participantes e a professora, traçando conexões com teorias de outros/as autores/as da área.

A participação como pesquisadora na etapa também propiciou o acompanhamento de algumas atividades dos/as outros/as professores, das áreas de concentração "Ciências da Natureza e Matemáticas" e "Linguagens e Artes". No final da etapa foi realizado um encontro com as apresentações dos trabalhos desenvolvidos nas três áreas.

A turma da área "Linguagens e Artes" cursou a disciplina "Cultura corporal e povos indígenas", desenvolvendo trabalhos de pesquisa sobre as manifestações corporais da etnia Assurini do Tocantins e seus significados, incluindo danças, esportes e brincadeiras, fazendo entrevistas com pessoas mais velhas da aldeia, buscando identificar o que mudou na cultura corporal e se existem interferências da cultura ocidental.

Esses trabalhos incluíram uma atividade com apresentação de danças na escola, formando dois grupos e ensaiando com turmas de alunos duas músicas diferentes: Arytinga Se'engara e Wyracakawa, fazendo pinturas corporais nas crianças, específicas para cada dança. $O$ evento contou com a participação de dois idosos da comunidade, os quais fizeram demonstração das danças, orientando os movimentos e cantando junto com as crianças. Após a apresentação, houve uma fala de alguns professores e do cacique, enfatizando a importância da língua, das danças, das músicas e da pintura corporal, salientando a necessidade de não esquecer e de não ter vergonha da cultura.

Essa disciplina também proporcionou a organização de um encontro cultural, na parte da noite, com a presença de grande parte da

\footnotetext{
${ }^{9}$ Método organizado por Jorge Gaschê e seus colaboradores, na Amazônia Peruana. A proposta se fundamenta no uso das atividades territoriais cotidianas como produtoras de conhecimentos e aprendizagens.
} 
comunidade, incluindo lideranças e pessoas mais velhas. O centro cultural comunitário foi ornamentado com folhas de Inajá10, houve apresentações de danças e músicas, foram proferidos discursos e depois foi servido mingau de arroz para todas as pessoas presentes.

A turma "Ciências da Natureza e Matemáticas" cursou a disciplina "Saberes indígenas e estudos de biologia", desenvolvendo pesquisas com elaboração de roteiros e realização de entrevistas na comunidade, sobre assuntos diversos, como plantas medicinais, frutos, peixes, artesanatos, alimentos e pinturas corporais. As pesquisas originaram a produção de materiais pedagógicos para a escola, como cartazes, cartilhas e vídeos.

As três disciplinas organizaram um evento em conjunto, para a apresentação de todos os trabalhos desenvolvidos durante a etapa. Essa atividade proporcionou trocas de conhecimentos e sugestões mútuas entre os/as participantes e entre as turmas. Além do enriquecimento dos trabalhos, surgiram ideias para métodos de ensino, para novas investigações e para o aprofundamento das pesquisas realizadas.

\section{Reflexões}

Santos $(2011$, p. 56,59$)$ considera que a única forma efetiva de enfrentamento à globalização neoliberal se trata da confrontação com outro tipo de globalização, uma globalização alternativa, contrahegemônica, a partir da articulação entre universidades, forças sociais, indivíduos, coletivos organizados, organizações não governamentais, sindicatos e movimentos sociais, com um conjunto de iniciativas que aprofundem a responsabilidade social em direção a um conhecimento pluriversal e cosmopolita. O autor destaca a importância de integrar saberes de diversos atores sociais e fortalecer a interlocução entre Institutos de Ensino Superior e sociedade, de um modo direcionado para a resolução de problemas locais e a formação de redes maiores de colaboração e construção de conhecimento.

Processos de formação de professores/as indígenas como os descritos na parte inicial do texto, com suas articulações interculturais, interdisciplinares e interinstitucionais, apresentam potencialidades para esse tipo de discussão. As experiências contam com a participação de um conjunto de instituições e profissionais de diferentes áreas de conhecimento, abrangendo indígenas e não indígenas, proporcionando elementos significativos para processos de construção de outros tipos de saberes e ações educacionais, na direção de novas formas de globalização.

Essas construções podem ser pensadas a partir da inspiração em Santos (2002), na sua crítica ao modelo racional ocidental, a qual denomina razão indolente, por constituir um saber que apesar de se afirmar como exclusivo e completo, promove compreensão parcial e seletiva, seguindo uma ordem prescrita pela visão de totalidade, que supõe a preponderância do todo sobre suas partes, não permitindo que

\footnotetext{
${ }^{10}$ Palmeira nativa da região norte do Brasil, muito importante na cultura da etnia Assurini do Tocantins.
} 
estas sejam pensadas fora da relação com o todo. A simetria e homogeneidade dessa visão disfarça a hierarquia que se manifesta em relações dicotômicas, como entre conhecimento científico e tradicional, cultura e natureza, civilizado e primitivo, ocidente e oriente, além de outros inúmeros exemplos. Esse pensamento promove um imenso desperdício da riqueza proveniente da diversidade de experiências sociais e culturais.

A relação dicotômica e hierárquica de superioridade da cultura ocidental sobre a indígena é constatada em dizeres de participantes da disciplina "Interculturalidade na Educação Escolar Indígena", do curso de Licenciatura Intercultural Indígena da UEPA, como as palavras de Wakamuwia Assurini: "As diferentes culturas, indígena e não indígena, precisam caminhar juntas e não serem apresentadas de forma preconceituosa, em que uma é vista como mais importante que a outra, pois a discriminação prejudica muito os indígenas"; "Existem vários casos em que representantes da etnia Assuriní tentaram estudar fora, mas tiveram que retornar à aldeia sem concluir os estudos, por causa do preconceito".

Sobre essa questão, também pode ser destacada a fala de Imuwinawa Assurini:

O não indígena tem um olhar de julgamento, se colocando como superior aos outros povos e outras culturas, e vê a cultura indígena como sem valor. Existem pessoas que dizem ser capacitadas, estudadas e inteligentes, se considerando donas do conhecimento. Falam que sabem sobre os indígenas, mas não conhecem de perto e profundamente a realidade da cultura, e discriminam sem conhecer. (Imuwinawa Assurini, 2019).

Santos $(2010$, p. 137,144$)$ manifesta que o conhecimento, nas suas múltiplas formas, não está equitativamente distribuído na sociedade, sendo que o reconhecimento da diversidade epistemológica do mundo implica a renúncia a uma epistemologia geral, pois não há apenas conhecimentos muito diversos no mundo, mas também diferentes concepções sobre o que é considerado como conhecimento e quais seus critérios de validade.

Santos (2010, p. 92) desenvolve a ideia de que a transformação social deixe de ser pensada em termos ocidentais. Como um dos pontos de partida de Santos (2002), está o fato de que a compreensão do mundo ultrapassa a forma ocidental de compreensão e de legitimação do poder, a qual está relacionada com uma concepção espacial de totalidade que causa uma contração do presente; e uma concepção temporal linear que ocasiona uma expansão do futuro. Como processo de transição para uma racionalidade cosmopolita, o autor sugere uma expansão do presente, a partir da sociologia das ausências, e uma contração do futuro, através da sociologia das emergências. E para a compreensão mutua entre as experiências geradas por essas trajetórias, um trabalho de tradução. 
A dilatação do presente é proposta por Santos (2002, p. 245) a partir de mecanismos que proporcionem a coexistência da razão indolente com outras totalidades, bem como o fortalecimento da vida própria das partes, para além do todo. O autor parte da compreensão dos mecanismos de produção da não-existência, se referindo às lógicas monoculturais e as respectivas formas de não-existência produzidas: a lógica da monocultura do saber (ignorância), do tempo linear (atraso), da classificação social (inferioridade), da escala dominante (local) e dos critérios de produção capitalista (improdutivo).

O indígena, em geral, é visto por nossa sociedade como ignorante, atrasado, inferior, local e improdutivo, isto é, correspondendo a todas as formas de produção de não-existência. Observações, escutas e diálogos desenvolvidos ao longo das referidas experiências de formação docente mostraram uma série de depoimentos e expressões indígenas sobre impactos de todo um processo colonizador e de imposição de uma racionalidade. Alguns exemplos são trazidos a seguir, a partir falas de professoras e professores indígenas, registradas durante as etapas das formações continuadas acompanhadas no alto rio Negro: "A gente tem timidez como profissionais, falta autoconfiança"; "Esta desvalorização que nós temos está prejudicando nossa forma de trabalhar".

A falta de valorização dos saberes indígenas, inclusive de suas línguas, afeta profundamente sua identidade, como mostram os depoimentos a seguir: "Os pais não sabem mais o que é a cultura indígena, tem alunos que nem sabem como fazer beiju"; "Os pais não querem por causa dos brancos, querem cultura branca, tem vergonha da própria cultura"; "Muitos alunos não querem mais saber da língua materna, dizem que não são mais indígenas"; "A comunidade não decide o que quer: dizem que querem aprender a língua indígena, mas quando o professor trabalha falam que querem só o português".

Essas falas indicam sentimentos de inferioridade, falta de confiança e desvalorização da própria cultura, mostrando como atuam os mecanismos de produção de não-existência, impactando a identidade indígena. A repetição ao longo do tempo da atuação desses mecanismos de produção de não-existência vai provocando processos intensos de erosão cultural, com perdas de importantes conhecimentos. Santos (2010, p. 87) chama de epistemicídio a morte do conhecimento ocasionada aos grupos sociais submetidos a essa colonização do saber.

Mas para cada um dos domínios citados, Santos (2002, p. 250) sugere mecanismos de superação das lógicas, no sentido de revelar e valorizar a diversidade de práticas sociais. Assim, para a lógica da monocultura do saber é sugerida a ecologia de saberes; para a lógica do tempo linear, a ecologia das temporalidades; para a lógica da classificação social, a ecologia dos reconhecimentos; para a lógica da escala dominante, a ecologia das trans-escalas; e para a lógica dos critérios de produção capitalista, a ecologia da produtividade.

O presente texto se direciona principalmente para a ecologia de saberes, como mecanismo de superação da lógica da monocultura do saber, mas também como potencialidade de contribuição para a atuação nas outras lógicas e em seus mecanismos de superação, como forma de 
proporcionar a visualização da relevância de outros tempos, escalas, identidades e modos de produção.

A ecologia de saberes é sugerida por Santos et al (2006, p. 79) como uma possibilidade para se pensar a descolonização da ciência, constituindo uma posição epistemológica em que são asseguradas igualdades de oportunidades aos diversos conhecimentos, visando potencializar suas contribuições na concepção de uma sociedade mais justa, ecológica e democrática.

Conforme Santos (2006), a Ecologia dos Saberes parte da premissa da existência e do reconhecimento afirmativo da diversidade epistemológica do mundo, da diversidade cultural e de uma pluralidade de formas de conhecimento. O autor sugere alguns cuidados para a ecologia de saberes, como espaço democrático, ambiente inclusivo e acolhedor, processo coletivo de produção de conhecimentos, paciência, escuta e tradução (CARNEIRO et al 2014, p.332), os quais também foram identificados nas experiências de formação docente investigadas.

Falas indígenas durante essas experiências formativas mostraram conhecimentos importantes que podem contribuir com diversas áreas de conhecimento, como educação, ecologia, saúde e organização social. Algumas ideias são trazidas aqui para exemplificar e potencializar a discussão.

Relevantes saberes conceituais e metodológicos são oferecidos para a área da educação, a partir da pedagogia tradicional indígena e das suas experiências em processos de construção da Educação Escolar Indígena Diferenciada, trabalhando questões pedagógicas atuais, como interdisciplinaridade, interculturalidade, multidimensionalidade e relação entre teoria e prática.

A colaboração para uma prática pedagógica interdisciplinar pode ser exemplificada nesses depoimentos registrados durante as etapas do curso Aperfeiçoamento em Educação Escolar Indígena: "O que estou estudando na sala de aula está relacionado com o que está no rio, na mata, na roça. É a nossa ciência, a aprendizagem é integrada"; "Ensinamos a matemática com elementos da natureza, junto com ciências e geografia; pesquisando formas geométricas da natureza e das pinturas corporais"; "Com o trabalho de pesquisa sobre a história da comunidade, envolvemos todas as disciplinas, o cuidado com o ambiente, a caça, a pesca, a coleta de fibras e frutos silvestres"; "Trabalhamos com plantas medicinais, benzimentos, construção de canoas, histórias sobre o mato, os animais e as plantas".

O acompanhamento da etapa da Licenciatura Indígena da UEPA também possibilitou ideias interessantes nessa direção. Wakamuia Assurini trouxe o exemplo do ensino da matemática na prática, com frutas, sementes e outros elementos da natureza, usando diferentes espaços da aldeia; e da área da geografia, relacionando com o território indígena e o cotidiano da comunidade. Urenia Assurini ressaltou a importância de trabalhar na escola a preservação da floresta e os conhecimentos tradicionais, levando os alunos para pesquisar com os mais velhos, construindo desenhos, cartazes e vídeos. Moiratsin Assurini relatou algumas dessas atividades que são desenvolvidas pelos/as 
professores indígenas, como os trabalhos com cartazes e desenhos de animais; e as pesquisas feitas com os mais velhos sobre os usos das plantas, gravando com o celular e levando plantas medicinais pra escola.

A arte é apresentada como um potencial elo de ligação entre as diversas áreas de conhecimento, com fundamentos éticos, trazendo mensagens espirituais e afetivas, além de constituir um elemento fundamental para registros e expressões de saberes indígenas. Estas falas de participantes do curso "Aperfeiçoamento em Educação Escolar Indígena" mostram a relevância da arte na função do educador: "O professor também precisa ser artista. Como ensinar práticas de sobrevivência, artes tão vivas, pinturas, caça, pesca, brincadeiras, danças, vestimentas, festas? Como comunicar?"; "As crianças gostam muito quando a gente trabalha com história e desenho. As mensagens das histórias sempre estão ligadas a dificuldades e potenciais da vida, como essa: pra não perder tem que estar junto".

A arte, além de integrar culturas e áreas de conhecimento, possui o potencial de trabalhar com diferentes dimensões do ser humano, de modo a não priorizar o trabalho mental, mas fortalecer também o físico, emocional, intuitivo e espiritual, lidando com a afetividade, o sentimento e o simbolismo. Como exemplo, podemos destacar o depoimento emocionado de uma professora indígena do curso Aperfeiçoamento em Educação Escolar Indígena, após a atividade de escrever e desenhar histórias de sua infância: "Gostei muito de trabalhar o lado afetivo. Coisas de quando eu era criança, como as histórias que eram contadas. Nunca imaginei que iria escrever e desenhar isto".

O lúdico também se mostrou como elemento importante na educação indígena. Muitas vezes solicitavam a realização de dinâmicas e brincadeiras, para "alegrar as aulas", e se referiam aos jogos que faziam em suas escolas e comunidades: "Nas comunidades as crianças conhecem muitas brincadeiras e jogos. O professor pode ajudar a construir as regras do jogo".

Brincar é pedagógico. Tive muitas experiências no trabalho, como na vida. Quando fui pra cima, na escola da comunidade Juruti, numa ilha, eles tinham perdido a língua. Eu fazia brincadeiras onde todo mundo participava, até os velhos, toda a comunidade. Fazia barquinho de madeira e palha, amarrado com cipó, material todo da cultura mesmo. Frutas, verduras, peixe, caruru, saúva, tucupi, tudo da região, que é rica em alimento. Tinha abertura, cada responsável de barraquinha criava uma brincadeira. Criava dinheiro falso e distribuía nas barracas. Criança, velho, adulto, tudo. Cada brincadeira e comida tinha seu valor. Era o dia todo. $\mathrm{Na}$ noite tinha apresentação da cultura, mito, história, piada. No fim viam quem era o vencedor da barraca, quem ganhava mais. Fazia brincadeira que anima, ativa as pessoas. É muito bom a gente 
brincar. Todo mundo participa. Ninguém fica lá sentado. (Professor indígena, 2015).

Outra abordagem relevante da pedagogia indígena, observada das experiências de formação de professores, trata-se da preferência pelo coletivo. O seguinte depoimento mostra a importância da coletividade para a aprendizagem indígena e como isso precisa ser trazido na educação escolar e na formação de professores/as:

No trabalho em grupo a gente vai se ajudando. Um sabe melhor o desenho, outro tem a letra melhor, outro a língua indígena, outro o português. O curso proporciona integração entre etnias e grupos, e aprendo com as ideias dos colegas. Cada um tem uma comunidade, uma realidade diferente. No curso ficamos conhecendo, trocando. Aprendo com cada um alguma coisa, reaprendo o que já tinha esquecido. Os professores brancos também aprendem com nossa cultura. A gente aprende mais como organizar o conhecimento, como trabalhar com os alunos. Importante levar isso pra comunidade. (Professor indígena, 2015).

A preferência pelo coletivo foi nítida, não somente no que diz respeito aos "parentes", modo como se referem aos indígenas de qualquer etnia, mas na relação com não indígenas, como exemplificada nessa fala de um professor Baniwa: "Eu gosto de parcerias com instituições e pessoas, a gente aprende muito".

Foi também muito evidente a presença de conhecimentos relacionados com a ecologia, de grande relevância para as questões ambientais da atualidade: "A natureza pra nós é como se fosse nosso irmão. Se tem cinco cachos de banana, vamos tirar só o que precisamos"; "Precisa educar o país, mostrar como os indígenas aprenderam a viver milenarmente sem destruir a natureza. Precisa construir o bem viver defendido pelos povos indígenas."

O Bem Viver, conforme Bailone (2012), se refere ao paradigma indígena constituído por uma vida de harmonia entre humanidade e natureza. Na Bolívia é utilizado o termo "Vivir Bien" e no Equador "Buen Vivir", aludindo às palavras suma gamaña em aymara e sumak kawsay em quechua. Como explica Mamani (2010, p.79), significa uma vida de relação de respeito por todos os elementos da existência, fundamentada na concepção de que tudo está conectado e que o dano a uma parte afeta seu conjunto, deteriorando a vida.

Estes são apenas alguns exemplos de sistemas complexos e profundos de conhecimentos e práticas, os quais passam por movimentos de resistência, mas que sofrem pressões constantes, com fortes impactos de deterioração. As trajetórias de revitalização e documentação de saberes ameríndios, vivenciadas durante atividades de formação de professores/as, mostram campos de potencialidades para construções de 
alternativas transformadoras da realidade, conforme demandas das aldeias, das ações do movimento indígena e de suas relações com a sociedade.

Portanto, também pode ser traçada uma ligação desses processos formativos docentes com a sociologia das emergências, sugerida por Santos (2002, p. 256), a qual se refere a investigações das alternativas existentes nas possibilidades reais do tempo presente, identificando sinais, pistas ou traços de possibilidades futuras, visando substituir o vazio do futuro da temporalidade linear por um futuro de possibilidades concretas, construídas no presente através de ações de cuidado, nos variados campos sociais. É necessário fortalecer essas pistas e sinais, expandindo o campo de possibilidades das experiências sociais, para que a ampliação de experiências credíveis possa proporcionar a construção, a partir do presente, de outros tipos de futuro. O autor sugere as seguintes áreas como mais importantes para a manifestação da diversidade e da multiplicidade: experiências de conhecimentos; experiências de desenvolvimento, trabalho e produção; experiências de reconhecimento; experiências de democracia; experiências de comunicação e de informação.

As formações de educadores/as indígenas oferecem sinais de experiências em todos esses âmbitos. São experiências de conhecimentos, pois possibilitam levantamentos e registros de saberes de diferentes áreas, como saúde, educação, manejo ambiental e produção de alimentos. Proporcionam experiências de desenvolvimento, trabalho e produção, como a visualização de potencialidades para criação e comercialização de produtos ecológicos, organização de cooperativas, participação em feiras de economia solidária, etc. Integram experiências de reconhecimento de diferentes etnias e culturas, através dos processos interculturais de ensino, aprendizagem e produção de conhecimento. Trazem propostas de experiências democráticas, construídas ao longo dos processos de elaboração, planejamento e execução de atividades, com tomadas de decisão que fortalecem diferentes opiniões, com base em princípios como reciprocidade e valorização do coletivo.

Constituem ainda experiências de comunicação e de informação, possibilitando usos específicos de redes sociais e programas informáticos para construções de teias de comunicação, produtos e materiais pedagógicos; difusão de conhecimentos indígenas; e criação de programas que atendam a demandas emergentes dentro de perspectivas descolonizadoras. Conforme revelado de diferentes formas durante o curso, o fortalecimento das etnias e comunidades indígenas também passa pela revitalização e o registro de seus conhecimentos, sendo que as Tecnologias de Informação e Comunicação exercem um papel importante nesse processo: "Nossos velhos são bibliotecas, se morrem se perde. Precisamos lembrar o que foi esquecido"; "Tem que filmar, relatar, escrever, desenhar. Precisamos de CD, computador, HD externo, são também nossas ferramentas."

Falas como essas mostram um importante papel dos processos de formação de professores/as indígenas como apoio para a reconstrução de suas memórias, proporcionando instrumentos para a compilação, 
organização e registro de saberes. Essa função traz a importância de se refletir e praticar relações interculturais que contribuam para a valorização do pensamento indígena e a descolonização da educação.

Conforme Santos (2002, p. 261), os processos que possibilitam a visualização das experiências disponíveis e possíveis, respectivamente a partir da sociologia das ausências e das emergências, trazem à tona a questão da grande fragmentação da realidade, e da impossibilidade de uma grande teoria geral explicativa que possa oferecer sentido à transformação social.

Nesse sentido, o trabalho de tradução é apresentado por Santos (2002, p. 262) como mecanismo que permite a inteligibilidade recíproca entre as experiências do mundo, disponíveis e possíveis, que vão sendo reveladas nesse duplo movimento das sociologias das ausências e das emergências. Esse trabalho incide sobre os saberes as práticas e seus agentes, em um processo de tradução e interpretação entre diferentes culturas, de modo a proporcionar a agregação entre saberes para a construção de visões contra-hegemônicas.

Santos (2002, p. 294) sugere a hermenêutica diatópica, partindo de uma concepção de que todas as culturas são incompletas e podem ser enriquecidas pelo diálogo e o confronto com outras culturas. A ideia de incompletude cria a motivação para o trabalho de tradução, que precisa se configurar na intersecção de impulsos nas e das diferentes culturas. Esse processo, de acordo com Santos (2002, p. 297), visa criar inteligibilidade, coerência e articulação em uma realidade enriquecida pela diversidade e multiplicidade.

A noção de tradução também é trazida por Fornet-Betancourt (2007, p. 50-64), em uma sugestão de reformular o sentido da educação, como uma esfera intercultural de culturas que se traduzem mutuamente, no cultivo cotidiano de relações envolventes e reflexivas, se redimensionando e melhorando continuamente através do acesso a outras perspectivas culturais. O autor destaca a importância da criação de espaços interculturais, nos quais as culturas se revitalizam por meio da interação com as demais, aprendendo a pensar de outras formas e construindo pensamentos e conhecimentos.

A formação de professores/as indígenas pode se constituir em campos de tradução, quando construídas em visões de incompletude e complementaridade entre diferentes culturas, sem a supremacia do conhecimento ocidental. Essa visão é trazida por professores/as indígenas no que se refere aos objetivos da educação intercultural. Iwitoarawia Assurini, por exemplo, ressalta a importância de que alunos indígenas possam reconhecer e manter a diversidade cultural, relacionando sua própria história, mitos, danças, rituais, artesanatos, pinturas e modos de preparar alimentos, com a cultura não indígena, a fim de ter o entendimento da sua realidade cultural e respeitar os conhecimentos e identidade étnica de diferentes sociedades. Portanto, a função da escola é mostrar a importância de valores de respeito às diferentes culturas, desenvolvendo habilidades teóricas e práticas.

Moiratsin Assurini acrescenta a necessidade de conhecer tanto a realidade indígena, como as outras sociedades, de modo a identificar os 
conhecimentos de cada povo. Para um desenvolvimento intercultural, existem alguns conhecimentos relevantes, como o da identidade indígena e do direito à terra, cultura, língua e saúde. Também é importante desenvolver o respeito e a organização. Construir a escola intercultural requer não só uma intensa experiência, mas também métodos de pesquisa para compreender melhor a cultura.

Segundo Santos (2010, p. 152), as perspectivas interculturais tem vindo a permitir o reconhecimento da existência de sistemas de saberes plurais, alternativos à ciência moderna ou que com esta se articulam em novas configurações de conhecimentos. Na área da educação, por exemplo, Imuinawa Assurini ressalta a importância da interculturalidade no ensino prático, trazendo o conjunto de atividades ligadas à roça como exemplo de potencial de pesquisa e prática de temas interculturais, envolvendo o preparo da área, o plantio, a colheita e a comercialização de produtos, trabalhando conhecimentos e valores indígenas e ocidentais.

Para Santos (2002, p. 273), o objetivo mais amplo da sociologia das ausências, das emergências e do trabalho de tradução, se refere ao desenvolvimento de alternativas à razão indolente, na forma do que o autor denomina razão cosmopolita, com base na visão da impossibilidade de existir uma justiça social global sem uma justiça cognitiva global. Constituem trabalhos de imaginação epistemológica e democrática, visando à criação de novas e diversas formas de emancipação social e condições para justiça social global, o que exige que as constelações de sentido criadas pelo trabalho de tradução se transformem em práticas transformadoras.

\section{Considerações Finais}

Algumas constatações fundamentais podem ser traçadas a partir do processo reflexivo desenvolvido com base no diálogo entre falas indígenas, no âmbito da formação docente, e categorias do pensamento do autor Boaventura de Souza Santos.

Marcas colonizadoras são nítidas, por um lado, em dizeres que demonstram sentimentos de inferioridade e de que a outra cultura é melhor, inclusive em etnias de recente contato. Além disso, na constatação da existência de diversos tipos e níveis de discriminação e preconceito. Os mecanismos de fabricação de ausências, conforme descritos pelo autor, continuam fortalecendo dicotomias entre primitivo e civilizado, desenvolvido e atrasado, superior e inferior, produtivo e improdutivo, global e local. Pensamentos integracionistas seguem influenciando nossa sociedade, com a visão de que povos indígenas precisam ser submetidos a uma padronização cultural, em um sistema hierárquico, onde são vistos como ignorantes, atrasados, inferiores, locais e improdutivos. Desse modo, dentro da lógica da racionalidade indolente, conhecimentos de grande complexidade e profundidade continuam sendo negados, provocando intensa erosão cultural. 
Por outro lado, a força da cultura indígena é muito grande, constituindo identidades de muita inteireza, em que os valores culturais essenciais continuam vivos. Processos de pesquisa dessas memórias, valorizando conhecimentos comunitários, principalmente dos mais velhos, de forma integrada à produção de materiais pedagógicos para as escolas, apresentam grandes potencialidades para a revitalização de saberes importantes para os povos indígenas e também para transformações sociais mais amplas, de grande relevância para nossa sociedade.

A Ecologia de Saberes, dentro de uma trajetória de tradução intercultural, revela conhecimentos complexos e detalhados sobre espécies de plantas e animais, aptidões práticas e teóricas sobre manejo sustentável de ecossistemas, ideias sobre educação, habilidades sofisticadas na construção e compreensão de sistemas linguísticos, talentos artísticos, informações geográficas e astronômicas.

Além do reconhecimento de saberes de diversas etnias, esses processos mostram potenciais para resolução de demandas das próprias aldeias, elaboração de estratégias de geração de renda, criação de produtos ecológicos e formas alternativas de comercialização, construção de propostas democráticas de acordos e tomadas de decisão, usos criativos de Tecnologias de Informação e Comunicação, etc.

Desse modo, a área da formação de professores/as indígenas se mostra como importante campo de investigação e processo de tradução intercultural, com o potencial de criação de pontes dialógicas entre diferentes culturas, na construção de sistemas educacionais criativos, práticos e transformadores, na produção de conhecimentos importantes para transformações sociais, de modo direcionado para a construção de uma razão cosmopolita. 


\section{Referências Bibliográficas}

BAILONE, Matías. El Bienvivir: una cosmovisión de los pueblos originários andinoamazónicos. In: ZAFFARONI, Eugenio Raúl. (Org.). La Pachamama y el humano. Buenos Aires: Colihue; Ciudad Autónoma de Buenos Aires: Ediciones Madres de Plaza de Mayo, 2012, p. 149-158.

BRASIL. Ministério da Educação e do Desporto, Secretaria de Ensino Fundamental. Referenciais Curriculares Nacionais para as Escolas Indígenas. Brasília: MEC/SEF, 1988.

CARNEIRO, Fernando Ferreira; KREFTA, Noemi Margarida; FOLGADO, Cleber Adriano Rodrigues. A Praxis da Ecologia de Saberes: entrevista de Boaventura de Sousa Santos. Tempus, actas de saúde coletiva, Brasília, v. 2, n. 8, p. 331-338, jun, 2014.

ENGEL, Guido Irineu. Pesquisa-ação. Educar em Revista, Curitiba, PR, n. 16, p. 18191, 2000.

EPPS, Patience. A grammar of Hup. 2005. 799f. Tese (Doutorado em Antropologia) University of Virginia, Charlottesville, Virginia, EUA, 2005.

FORNET-BETANCOURT, Raul. Reflexiones de Raul Fornet-Betancourt sobre el concepto de interculturalidad. México: CREFAL, 2007.

FUNAI. Plano Plurianual 2012-2015. Programa de proteção e promoção dos direitos dos povos indígenas. 2012. Disponível em: http://www.funai.gov.br/arquivos/conteudo/ouvidoria/pdf/acesso-ainformacao/Plano_plurianual-PPA_2012-2015.pdf. Acesso em: 04 maio. 2019.

MAMANI, Fernando Huanacuni. Buen Vivir / Vivir Bien Filosofía, políticas, estrategias y experiencias regionales andinas. Lima: Coordinadora Andina de Organizaciones Indígenas - CAOI. 2010. 120 p.

SANTOS, Boaventura de Souza. Para uma sociologia das ausências e uma sociologia das emergências. Revista Crítica de Ciências Sociais, n 63, Coimbra, Outubro 2002: 237280.

SANTOS, Boaventura de Souza; MENEZES, Maria Paula; NUNES, João Arriscado. Conhecimento e transformação social: por uma ecologia de saberes. Hiléia: Revista de Direito Ambiental da Amazônia. ano 4, n. ${ }^{\circ}$ 6. Manaus: Edições Governo do Estado do Amazonas / Secretaria de Estado da Cultura / Universidade do Estado do Amazonas, 2006. P.11- 104 .

SANTOS, Boaventura de Souza. A gramática do tempo. São Paulo: Cortez, 2006.

SANTOS, Boaventura de Sousa; Maria Paula Meneses (orgs.). Epistemologias do sul. São Paulo: Cortez, 2010. 
Espaço Ameríndio

SANTOS, Boaventura de Sousa. A universidade no século XXI: para uma reforma democrática e emancipatória da universidade. São Paulo: Cortez, 2011.

Recebido em: 22/07/2019* Aprovado em: 14/06/2020* Publicado em: 16/12/2020 